\title{
IRUPÉ: SITIO WEB DE IMÁGENES DE LA FLORA NATIVA DE ARGENTINA ASOCIADO AL HERBARIO SF
}

\author{
Paye, I. A. ${ }^{1} ;$ Pensiero, J. F. ${ }^{2,3} ;$ Grenón, D. A. ${ }^{1,3}$ \& EXner, E. ${ }^{2}$
}

\begin{abstract}
RESUMEN
Se presenta un sitio web de una base de datos que permite la consulta de más de 32.000 imágenes relacionadas con la vegetación y flora nativa de Argentina. Las imágenes ilustran características de hábitat, hábito y detalles morfológicos de 2.250 especies, y relaciona 8.000 nombres vulgares con 4.187 nombres científicos de la flora de Argentina. La mayoría de las imágenes correspondientes a las especies están relacionadas con ejemplares de referencia depositados en el Herbario "Arturo E. Ragonese” (SF). La base de datos permite diferentes criterios de búsquedas: por nombre científico, nombre vulgar y ecorregión, entre otras.
\end{abstract}

Palabras claves: Base de datos, imágenes, flora, Argentina, herbario.

\begin{abstract}
Irupé: website of images of the Argentina's native flora associated with the Herbarium SF.

We present a web site of a database that allows the consultation of over 32,000 images related to the native vegetation and flora of Argentina. The images illustrate habitat, habit and morphological details of over 2,250 species, and it relates 8,000 common names with 4,187 scientific names of the Argentina flora. Most of the images are related to reference specimens deposited in the Herbarium “Arturo E. Ragonese” (SF). The database allows various search criteria: by scientific name, common name and ecoregion, among others.
\end{abstract}

Key words: Data Base, images, flora, Argentina, herbarium.

1.- Cátedra de Agromática, Facultad de Ciencias Agrarias, Universidad Nacional del Litoral. Kreder 2805. 3080HOF, Esperanza, Santa Fe, Argentina.

2.- Cátedra de Botánica Sistemática Agronómica, Facultad de Ciencias Agrarias, Universidad Nacional del Litoral. Kreder 2805. 3080HOF, Esperanza, Santa Fe, Argentina. Email: jfpensi@fca.unl.edu.ar

3.- 1.- ICiAgro Litoral, Universidad Nacional del Litoral-CONICET, Facultad de Ciencias Agrarias. Kreder 2805. 3080HOF, Esperanza, Santa Fe, Argentina.

Manuscrito recibido el 24 de abril de 2020 y aceptado para su publicación el 31 de agosto de 2020.

Paye, I.A.; Penisero, J.F.; Grenón, D.A.; Exner, E. Irupé: sitio web de imágenes de la flora nativa de Argentina asociado al Herbario SF FAVE - Ciencias Agrarias 20 (1): 19-31. CC BY-NC-SA 4.0 


\section{INTRODUCCIÓN}

En el Herbario “Arturo E. Ragonese” (SF; Thiers actualización permanente) de la Facultad de Ciencias Agrarias (UNL), con una colección de unos 25.000 ejemplares, se documentan un total de 2.532 especies de la flora nativa de Argentina y el 95\% de la flora vascular que habita en la provincia de Santa Fe (Pensiero 2005).

Asociado al Herbario SF se dispone, producto de más de 30 años de trabajo, de una de las colecciones más importantes de imágenes fotográficas correspondientes a la flora nativa de Argentina, con más de 32.000 fotografías, a la que hemos denominado: IRUPÉ.

Con la finalidad de complementar y potenciar las funciones y objetivos del Herbario, y en procura de agilizar las tareas relativas al procesamiento, organización y consulta, se ha desarrollado una base de datos (BD) que facilita la administración y los usos académicos (docencia, investigación y extensión) de los ejemplares conservados y de las imágenes fotográficas. En una primera etapa, esta tarea se concretó en una BD relacional instrumentada sobre Microsoft Office Access $®$.

Para que esta colección esté a disposición de los docentes, investigadores, alumnos y público general que demanden su consulta, se ha codificado y puesto en línea un sitio web que posibilita la búsqueda de las imágenes según diversos criterios, tales como: nombre científico (familia, género, especie, subespecie, variedad), nombre vulgar, ecorregión de Argentina, divisiones políticas (provincia, departamento o partido), etc.

La flora vascular de Argentina está representada por 10.221 especies (Zuloaga et al. 2019), y si bien se carece aún de un tratamiento de conjunto de esta flora, en los últimos años se han publicado importantes contribuciones a nivel de familias (Anton y Zuloaga 2012, 2013, 2014 a, b, c y d, 2015 a y b, 2017, 2019, Zuloaga et al. 2012 a y b), contándose además, entre las más relevantes, con floras provinciales (Burkart 1969, 1974, 1979, 1987; Burkart y Bacigalupo 2005; Cabrera 1963, 1965 a y b, 1967, 1968, 1970, 1977, 1978, 1983, 1993; Kiesling 1994, 2003, 2009; Molina y Rúgolo de Agrasar 2006; Pensiero et al. 2005) y regionales (Arbo y Tressens 2002, Correa 1969, 1971, 1978, 1984 a y b, 1988, 1998, 1999). En estas obras, muchas de las especies tratadas se ilustran a través de dibujos o láminas en los que se resaltan las particularidades morfológicas diagnósticas, incluyéndose en algunos casos imágenes fotográficas de las mismas y menos comúnmente de sus hábitats.

No obstante los importantes avances que se han realizado para acceder on line a información actualizada, son escasos los sitios web en los que se pueden obtener imágenes fotográficas confiables (es decir, que la foto corresponda con la especie que se quiere ilustrar) de la flora nativa de Argentina. En relación con lo dicho, uno de los sitios más importantes en el que se puede acceder a imágenes de plantas argentinas corresponde al portal "Flora Argentina” (Flora Argentina 2018). Dicho portal incluye la totalidad de las especies vasculares reconocidas para nuestro país, ordenadas por familias, géneros y especies, aportando información sobre sus nombres aceptados, sinónimos, distribuciones geográficas, ejemplares de referencias, citas bibliográficas y en algunos casos, se ilustran las especies a través de láminas (dibujos) o fotos. Muchas de las imágenes fotográficas 
que se incluyen en este portal son créditos de uno de los autores del presente trabajo (J.F.Pensiero). Una desventaja que presenta este sitio, al igual que otros de Argentina que incluyen especies nativas, es que las fotos no se hallan respaldadas por un ejemplar de referencia. Es decir, un espécimen correctamente identificado y depositado en un herbario tal que permita su consulta ante alguna duda sobre la identidad taxonómica de la planta que se ilustra, aspecto éste que ha sido contemplado en la base de datos que se presenta. Por otra parte, una característica novedosa que posee este banco de imágenes es que se puede acceder al nombre científico aceptado de una especie, y a sus imágenes fotográficas, a través del nombre o nombres vulgares de la misma. Esto último de importancia para las actividades de extensión, dado que la mayoría de la gente no conocen los nombres científicos.

Se presenta el sitio web IRUPÉ, que permite la consulta "on line" del banco de imágenes de la flora argentina asociado al Herbario SF.

\section{MATERIALES Y MÉTODOS}

Desde el año 1981 (año al que corresponden las primeras imágenes fotográficas de esta colección) hasta el año 2005 (año en que se adquiere la primera cámara digital) se obtuvieron unas 5.000 fotografías de flora y vegetación de Argentina tomadas en diapositivas, las que fueron digitalizadas mediante un scanner Nikon LS-2000.

Tanto las imágenes escaneadas en alta resolución, como las originales en formato digital fueron duplicadas: el juego de originales fue conservado en su tamaño y resolución (debido a las variaciones en resolución dependiendo del tipo de cámara fotográfica empleada), mientras que las imágenes duplicadas fueron procesadas con un software específico que permite trabajar en simultaneo con lotes de imágenes (XnView 2020) a fin de uniformar y bajar los tamaños a 1200 x 900 píxeles (para que se ajusten mejor al tamaño de las pantallas y no sobrecargar las telecomunicaciones). A cada imagen se le incorporó una marca de agua en la que figura el número de registro en la base de datos y el autor de la fotografía o crédito fotográfico. Por último, se hizo una copia miniaturizada de cada fotografía para realizar con ellas las vistas previas de las imágenes, con la finalidad de acelerar la carga de los resúmenes de imágenes (Figura 1).

A través de un "formulario de carga" (Figura 2) cada fotografía va acompañada por un set de datos relativos a: número o registro de la foto, familia, género, especie, subespecie, variedad, observaciones, país, provincia, departamento/partido, localidad, fecha, ecorregión (cuando corresponde, si se trata de tipos de vegetación), crédito fotográfico, y datos del ejemplar de referencia que documenta o respalda la imagen, tales como coleccionista, número de colección y herbario donde se halla depositado.

En una primera instancia, la BD de las imágenes se diseñó en Microsoft Office Access ${ }^{\circledR}$ a fin de hacerla compatible y relacionarla con la $\mathrm{BD}$ de las colecciones del Herbario. Los formularios de ingreso, actualización y consulta de las imágenes se programaron con las herramientas disponibles en Access: consultas SQL y código en Microsoft Visual Basic para Aplicaciones $\mathbb{R}$ (VBA). 
I. A. Paye et al.

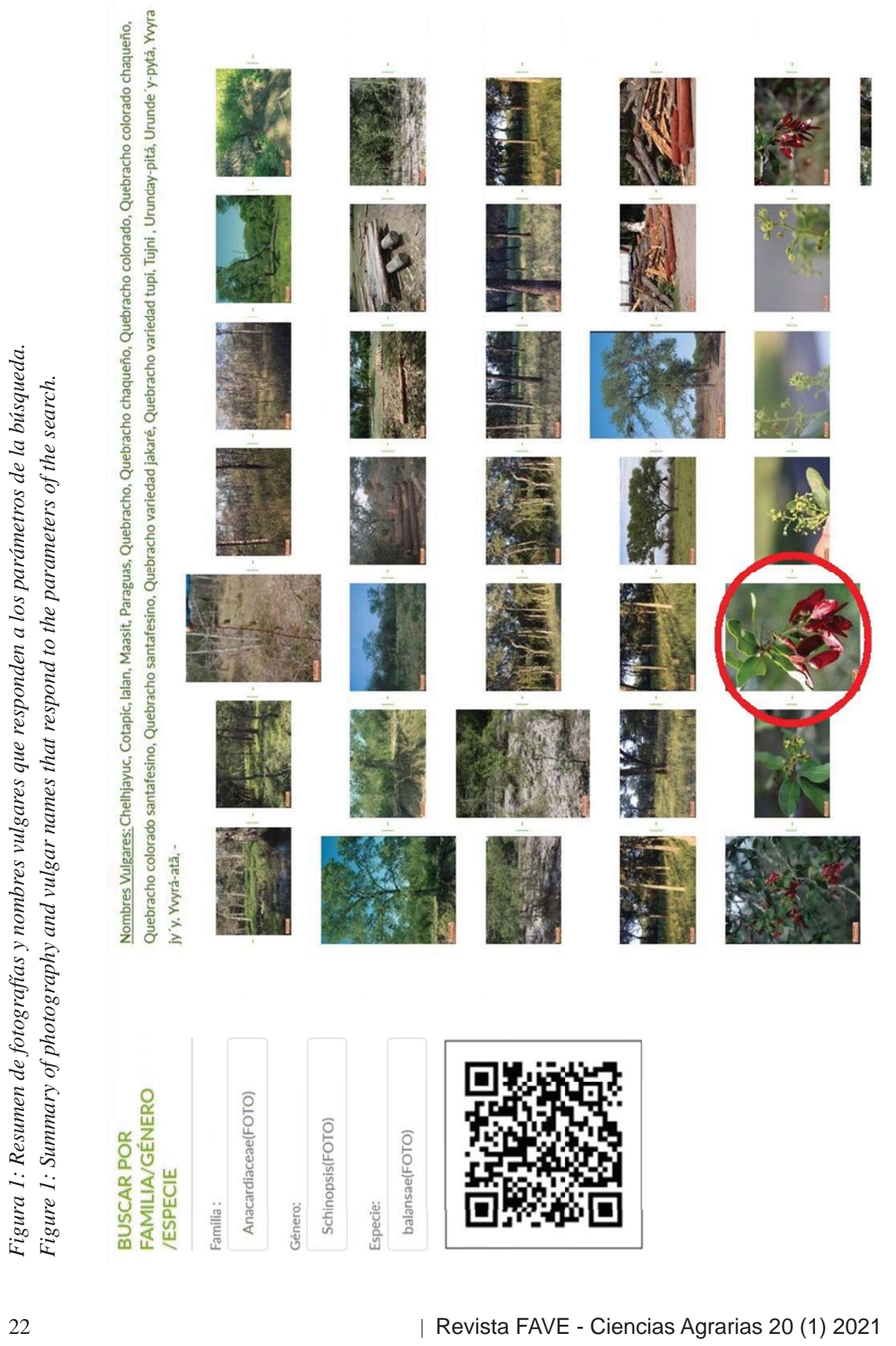


Irupé: imágenes de la flora nativa argentina

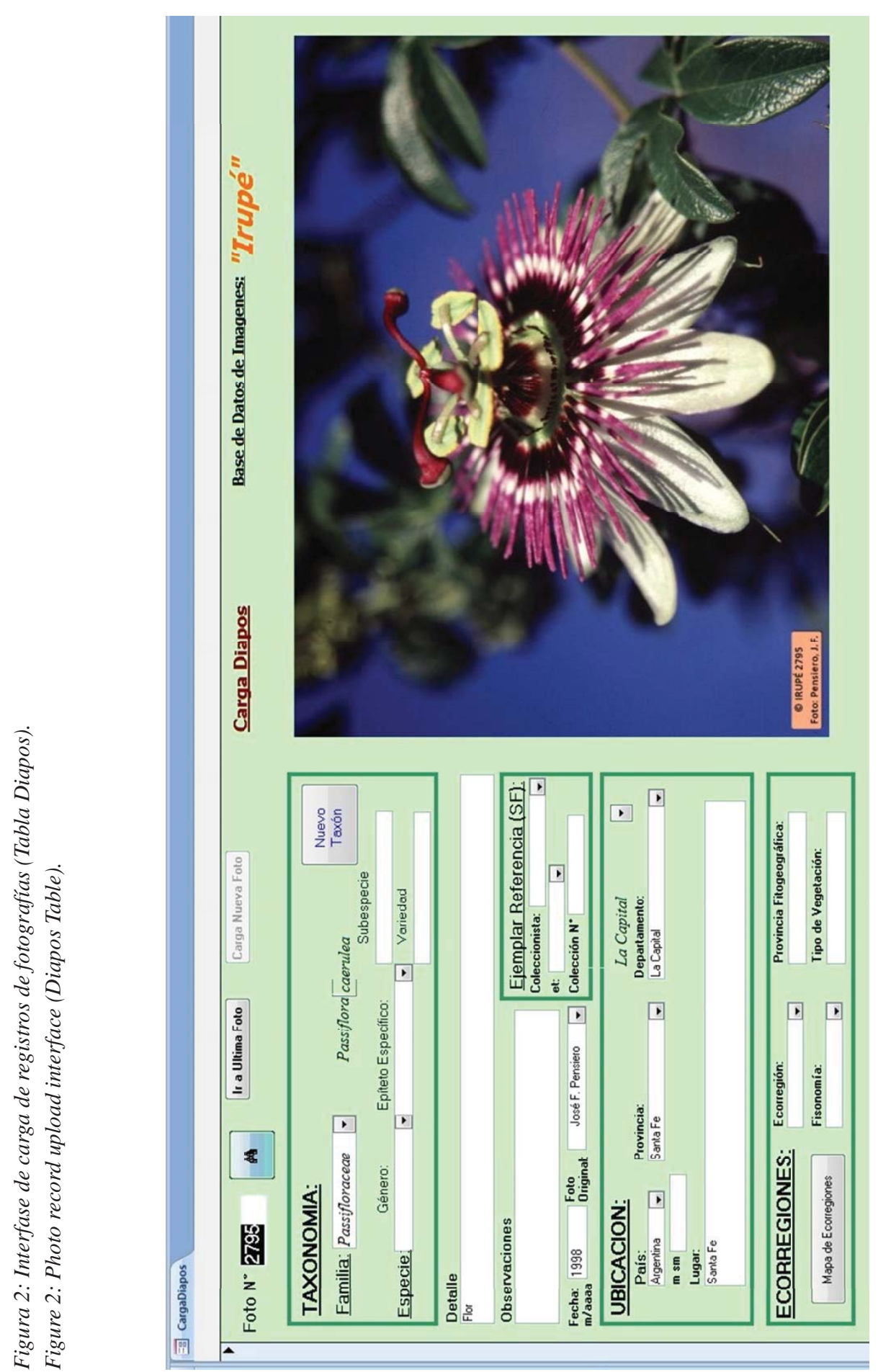

Revista FAVE - Ciencias Agrarias 20 (1) 2021 | 


\section{A. Paye et al.}

Para su publicación en la web, el banco de imágenes se organizó en una BD relacional MySQL y las consultas se realizan mediante páginas web dinámicas codificadas en lenguaje HTML5, PHP y, parte de la interfase de visualización, en JavaScript (Dhakar, 2020). Para esta tarea se utilizó el software libre WampServer (WampServer, 2020), el cual trabaja con los servicios Apache y PhpMyAdmin, el primero para las tareas en la estación de trabajo y el segundo para la administración de la BD MySQL. Para la codificación PHP y HTML se utilizó como editor, el software libre Notepad++ (2020). Para la subida de los archivos al servidor de la UNL se utilizó el software libre FileZilla (2020) por medio de protocolo de transferencia segura de archivos.

El sitio IRUPÉ se encuentra almacenado en los servidores web de la UNL y se puede consultar en https://www.fca.unl.edu.ar/ prodocova/IRUPE/index.html (Figura 3).
Se cuenta con protocolo de transferencia de hipertexto seguro (HTTPS), que es un protocolo de comunicación que protege la integridad y la confidencialidad de los datos de los usuarios entre sus ordenadores y el sitio web.

La tabla de relación de nombres vulgares y científicos de las especies se basó en el "Catálogo de nombres comunes de la flora argentina” (de la Peña y Pensiero, 2011), y la tabla de ecorregiones, en la publicación “Ecorregiones de la Argentina” (Burkart et al., 1999).

La nomenclatura de las especies que habitan en nuestro país sigue el criterio taxonómico adoptado en Flora Argentina (Flora Argentina 2018).

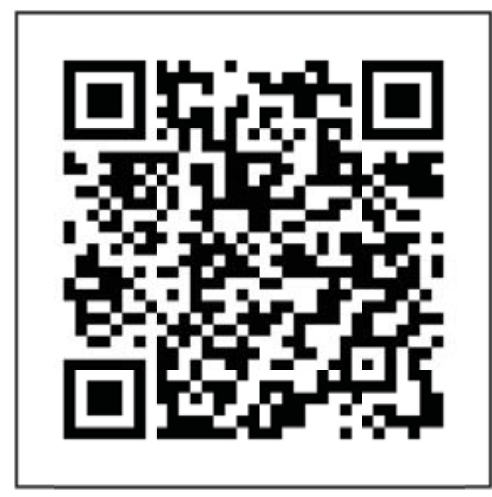

Figura 3: Código QR para acceso al sitio IRUPÉ.

Figure 3: QR code to access the IRUPÉ site. 


\section{RESULTADOS}

IRUPÉ contiene más de 32.000 imágenes fotográficas correspondientes a la flora de Argentina, y relaciona 8.000 nombres vulgares con 4.187 nombres científicos de especies, posibilitando de este modo la búsqueda tanto por nombre científico como por sus nombres vulgares. Se ilustran 2.250 especies correspondientes a 1.036 géneros y 182 familias, además de 2.913 fotografías de los tipos de vegetación característicos de cada ecorregión de Argentina.

\section{Modelo de datos entidad-relación}

El modelo de datos de IRUPÉ está integrado dentro del sistema de información del Herbario SF. La relación entre colecciones de imágenes y de especímenes es propia de las actividades de recolección de especímenes en dicho herbario: el coleccionista fotografía la planta, y sus detalles, previo a la recolección del ejemplar que se conservará. Luego, de la BD de colecciones se comparten con IRUPÉ las tablas Familia, Género, Especie y de la tabla Colección se relacionan con la tabla Diapos (Figura 4) de IRUPÉ los campos: Coleccionista, et al. (acompañantes en la Colección), Número de colección, Detalle, Observaciones, Ubicación, Fecha de colección, Coordenadas y Metros sobre el nivel del mar (msm).

Tabla Diapos: almacena el número de la imagen y datos referidos a su contenido: fecha de obtención, especie, ubicación geográfica (departamento/partido, lugar, latitud y longitud, altitud), ecorregión, tipo de vegetación, etc., más de 32.000 registros. El ejemplar de referencia de la imagen se obtiene a partir de la relación con la tabla Colección de la BD del Herbario SF.

Tabla Departamentos: listado de los departamentos/partidos de las provincias argentinas y algunos de provincias/estados de otros países (645 registros).

Tabla Provincias: listado de las provincias de Argentina y algunas de otros países (47 registros).

Tabla Países: listado de los países representados en la base de datos (6 registros).

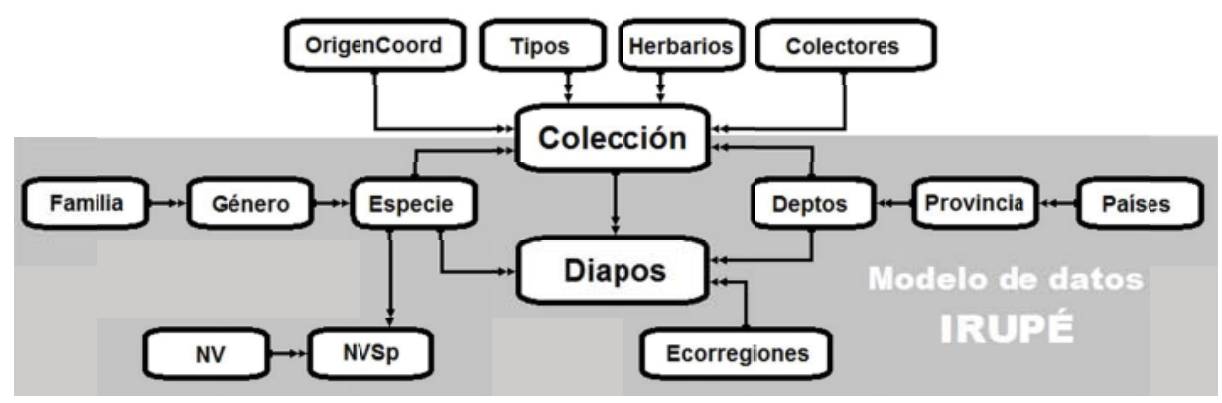

Figura 4: Relaciones de las tablas de la BD de imágenes IRUPÉ y las tablas de la BD del Herbario SF. Figure 4: Relationships of the IRUPE image DB tables and the SF Herbarium DB tables. 
Tabla Especies: listado de epítetos específicos y, en caso de corresponder, con identificación de subespecie y variedad (4.187 registros).

Tabla Géneros: listado de géneros (1.671 registros).

Tabla Familias: listado de familias (253 registros).

Tabla Ecorregiones: listado de ecorregiones de la Argentina (18 registros).

Tabla NV: listado de nombres vulgares (8.000 registros).

Tabla NVSp: tabla que relaciona los nombres vulgares con las especies, dado que una especie puede tener varios nombres vulgares y el un nombre vulgar puede representar a varias especies (incluso de géneros o familias distintas). Por ejemplo, para el nombre vulgar "cola de zorro" se han registrado 33 especies (Figura 5).

\section{Interfase de carga de fotografías}

Para la carga de las fotografías, previa a su disponibilidad en la web, se desarrolló un formulario en Microsoft Office Access ${ }^{\circledR}$ codificado en el lenguaje VBA de dicha aplicación (Figura 2). Este formulario permite cargar los registros fotográficos y relacionarlos con las restantes tablas. En el mismo lenguaje se desarrollaron los formularios de carga y consulta de fotografías por nombres vulgares (Figura 5) como también para la carga de nuevos taxones.

\section{Interfase del sitio web "IRUPÉ"}

La interfase está organizada para realizar los siguientes pasos:

(a) Opciones de búsqueda (Figura 6): permite seleccionar el criterio de búsqueda (por familia/género/especie, por nombre científico, por nombre vulgar, por ecorregión, por provincia, por departamento/partido).

(b) Carga de los parámetros de búsqueda según el criterio seleccionado. La palabra "(FOTO)" que aparece en algunos de los taxones listados indica para ese taxón que hay asociadas imágenes fotográficas (al menos una especie ilustrada en el caso de familias y géneros, o al menos un ejemplar en el caso de las especies). Cuando los taxones no están seguidos de la palabra "(FOTO)", indica que los nombres científicos de algunas especies de esas familias o géneros están asociados sólo a nombres vulgares y no se dispone, aún, de imágenes fotográficas.

(c) Presentación de un resumen de la totalidad de fotografías que ajustan a dichos parámetros (por ejemplo, familia, género y especie en la Figura 1). También aparece el listado de nombres vulgares que corresponden a la especie seleccionada.

(d) Visualización de la imagen seleccionada (Figura 7, fotografía 3400 por ejemplo) y presentación del contenido del registro: familia, género y especie; detalle de la fotografía; lugar y fecha de obtención de la fotografía; ejemplar de referencia en el Herbario SF (en la Figura 7 el ejemplar de referencia disponible en el Herbario SF, Pensiero et al. 6077, se muestra a la derecha). 


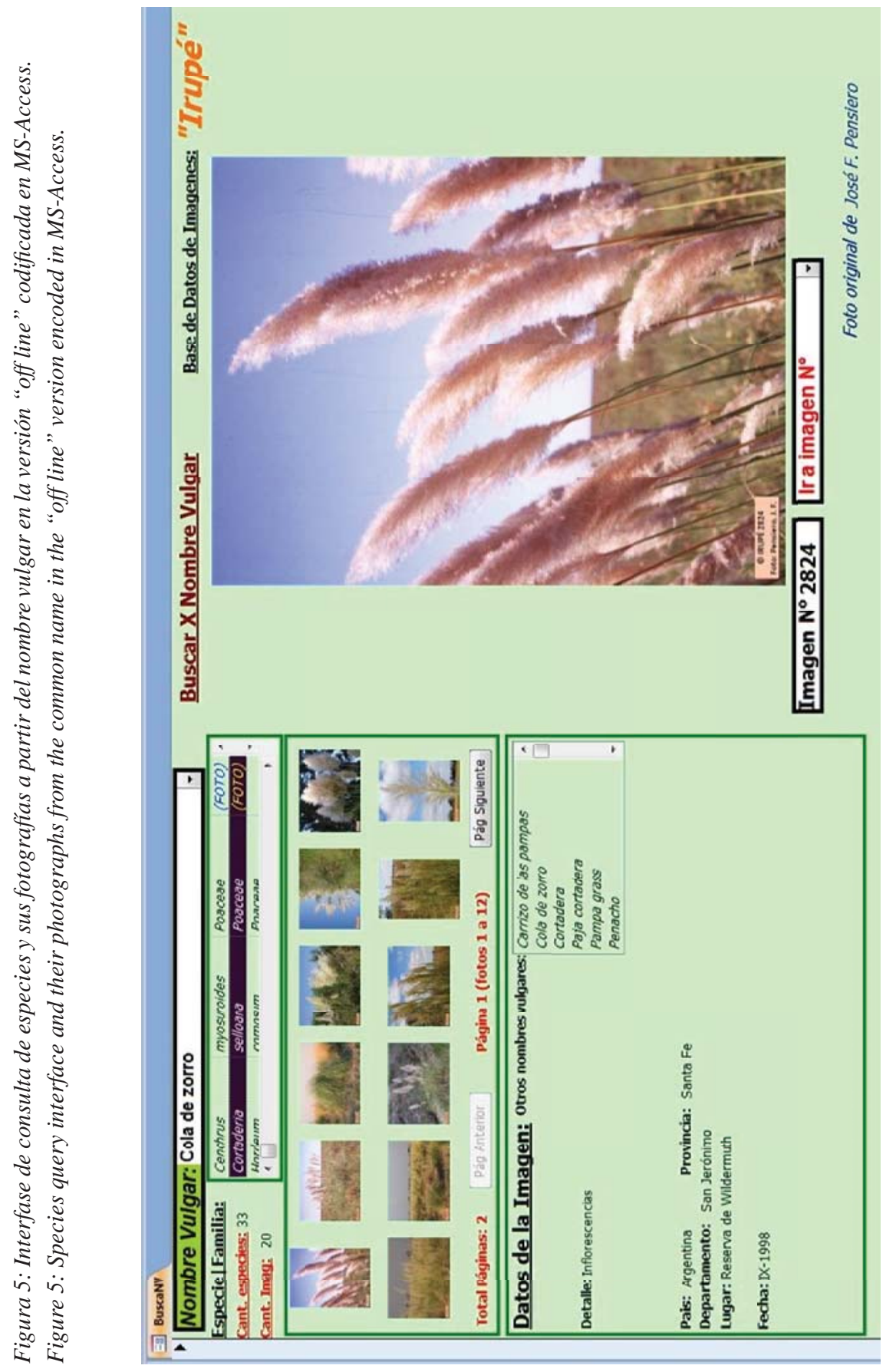

Revista FAVE - Ciencias Agrarias 20 (1) 2021 | 
I. A. Paye et al.
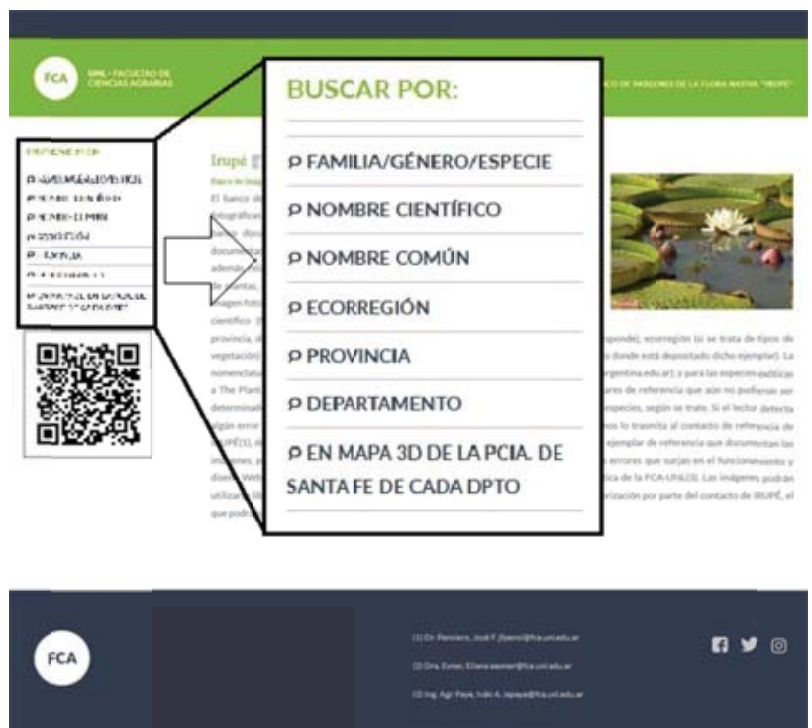

Figura 6: Pantalla de inicio del sitio IRUPÉ con las opciones de búsqueda de imágenes. Figure 6: IRUPÉ site home screen with image search options.

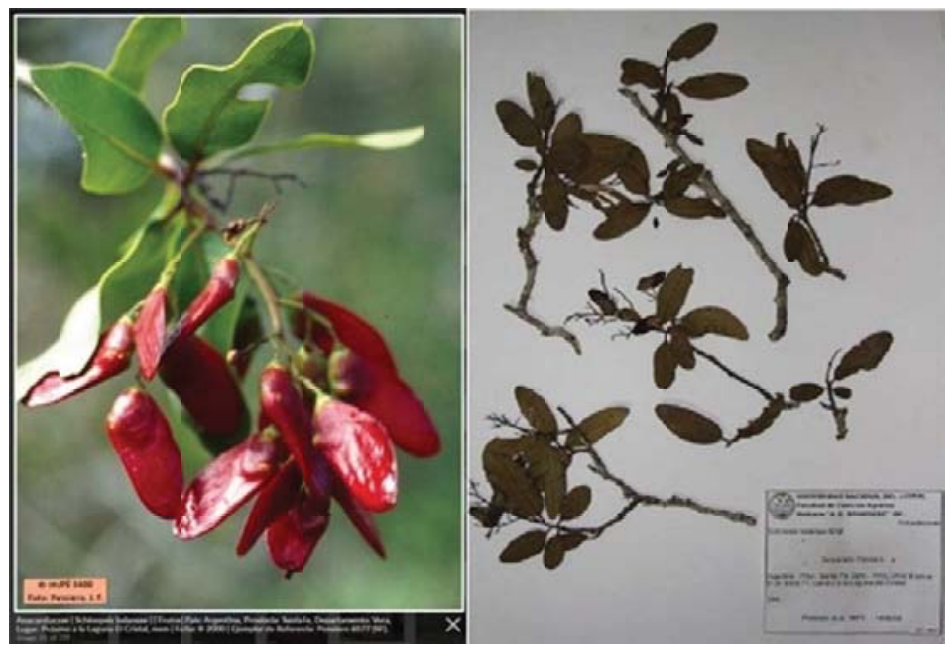

Figura 7: Detalle de la fotografía seleccionada en figura 1 y ejemplar de referencia en el Herbario SF. Figure 7: Detail of the photograph selected in figure 1 and reference copy in the SF Hebarium. 


\section{CONCLUSIONES}

La BD IRUPÉ es novedosa y única en su tipo para ilustrar la flora de Argentina, ya que posibilita, además de acelerar los procesos de carga y organización, la búsqueda de imágenes fotográficas a través de múltiples criterios: por familias, géneros, nombres científicos, nombres vulgares, provincias, departamentos/partido, etc.

La versión disponible en la web permite que cualquier usuario que desee realizar alguna búsqueda, pueda acceder a las imágenes en forma fácil y rápidamente, facilitando además relacionar las fotografías con las colecciones del Herbario SF.

A diferencia de otras BD de imágenes de flora, esta se distingue porque cada imagen va acompañada por: (a) un set de datos relativos al lugar, fecha y crédito fotográfico, (b) permite acceder a las imágenes y nombres científicos de las especies a través de la consulta por un nombre vulgar (cuestión fundamental para las actividades de extensión y trabajos escolares), y (c) las especies fotografiadas están documentadas con un ejemplar herborizado y conservado en el Herbario SF.

La web del Herbario SF está integrada al sitio ProDoCoVa (Programa de Documentación, Conservación y Valoración de la Flora Nativa, en https://www.fca.unl.edu. ar/prodocova/index.html ) y sirve de apoyo visual para el dictado de clases de diversas asignaturas. Este sitio pertenece a la Facultad de Ciencias Agrarias de la UNL dentro de sección Vinculación y este a su vez entre los Programas y Espacios Interinstitucionales. En dicho Proyecto se está trabajando en la generación de otras bases de datos (plantas tóxicas, árboles nativos, especies nativas melíferas, de interés en paisajismo, etc.) que se relacionarán con el banco IRUPÉ y con las colecciones del Herbario.

\section{BIBLIOGRAFÍA}

Anton AM, Zuloaga FO (Ed.). 2012. Flora vascular de la República Argentina Dicotyledoneae: Brassicaceae. Vol. 8. Córdoba: Graficamente Ediciones. 270 pp.

Anton AM, Zuloaga FO (Ed.). 2013. Flora vascular de la República Argentina Dicotyledoneae: Solanaceae. Vol. 13. Córdoba: Graficamente Ediciones. 350 pp.

Anton AM, Zuloaga FO (Ed.). 2014 a. Flora vascular de la República Argentina Licofitas, Helechos, Gymnospermas. Vol. 2. Córdoba: Graficamente Ediciones. 550 pp.

Anton AM, Zuloaga FO (Ed.). 2014 b. Flora vascular de la República Argentina Asteraceae: Anthemideae a Gnaphalieae. Vol. 7, Tomo 1. Córdoba: Graficamente Ediciones. 550 pp.

Anton AM, Zuloaga FO (Ed.). 2014 c. Flora vascular de la República Argentina Asteraceae: Senecioneae a Vernonieae. Vol. 7, Tomo 3. Córdoba: Graficamente Ediciones. 306 pp.

Anton AM, Zuloaga FO (Ed.). 2014 d. Flora vascular de la República Argentina Dicotyledoneae: Verbenaceae. Vol. 14. Córdoba: Graficamente Ediciones. 230 pp.

Anton AM, Zuloaga FO (Ed.). 2015 a. Flora vascular de la República Argentina Asteraceae: Cichorieae, Helenieae a Mutiseae. Vol. 7, Tomo 2. Córdoba: Graficamente Ediciones. 556 pp.

Anton AM, Zuloaga FO (Ed.). 2015 b. Flora vascular de la República Argentina Dicotyledoneae: Annonaceae, Aristolochiaceae, Atherospermataceae, Cabombaceae, Ceratophyllaceae, Hydnoraceae, Lauraceae, Monimiaceae, Nymphaeaceae, Piperaceae, Winteraceae. Vol. 25, Córdoba: Graficamente Ediciones. 118 pp.

Anton AM, Zuloaga FO (Ed.). 2017. Flora vascular de la República Argentina Celastrales, Cucurbitales, Fagales, Malpighiales, Oxalidales. Vol. 17. Córdoba: Graficamente Ediciones. 435 pp. 
Anton AM, Zuloaga FO (Ed.). 2019. Flora vascular de la República Argentina Dicotyledoneae: Apiales, Aquifoliales, Asterales, Bruniales, Dipsacales, Escalloniales, Solanales. Vol. 20, Tomo 2. Córdoba: Graficamente Ediciones. 444 pp.

Arbo MM, Tressens GS (Eds.). 2002. Flora del Iberá. Corrientes: Editorial Universitaria de la Universidad Nacional del Nordeste. 613 pp.

Burkart A, Bacigalupo N. 2005. Flora Ilustrada de Entre Ríos (Argentina). Tomo VI, Parte 4. Buenos Aires: Colección Científica INTA. 627 pp.

Burkart A. 1969. Flora Ilustrada de Entre Ríos (Argentina). Tomo VI, Parte 2. Buenos Aires: Colección Científica INTA. 551 pp.

Burkart A. 1974. Flora Ilustrada de Entre Ríos (Argentina). Tomo VI, Parte 6. Buenos Aires: Colección Científica INTA. 554 pp.

Burkart A. 1979. Flora Ilustrada de Entre Ríos (Argentina). Tomo VI, Parte 5. Buenos Aires: Colección Científica INTA. 606 pp.

Burkart A. 1987. Flora Ilustrada de Entre Ríos (Argentina). Tomo VI, Parte 3. Buenos Aires: Colección Científica INTA. 763 pp.

Burkart R, Bárbaro NO, Sánchez RO, Gómez DA. 1999. Ecorregiones de la Argentina. Buenos Aires: APN, PRODIA. 43 pp.

Cabrera AL. 1977. Flora de la provincia de Jujuy, República Argentina. Tomo XIII, Parte II. Buenos Aires: Colección Científica INTA. 275 pp.

Cabrera AL. 1978. Flora de la provincia de Jujuy, República Argentina. Tomo XIII, Parte X. Buenos Aires: Colección Científica INTA. 726 pp.

Cabrera AL. 1983. Flora de la provincia de Jujuy, República Argentina. Tomo XIII, Parte VIII. Buenos Aires: Colección Científica INTA. 508 pp.

Cabrera AL. 1993. Flora de la provincia de Jujuy, República Argentina. Tomo XIII, Parte IX. Buenos Aires: Colección Científica INTA. 560 pp.

Cabrera AL. 1963. Flora de la Provincia de Buenos Aires. Tomo IV, Parte 6. Buenos Aires: Colección Científica INTA. 443 pp.
Cabrera AL. 1965. Flora de la Provincia de Buenos Aires. Tomo IV, Parte 5. Buenos Aires: Colección Científica INTA. 434 pp.

Cabrera AL. 1965. Flora de la Provincia de Buenos Aires. Tomo IV, Parte 4. Buenos Aires: Colección Científica INTA. 418 pp.

Cabrera AL. 1967. Flora de la Provincia de Buenos Aires. Tomo IV, Parte 3. Buenos Aires: Colección Científica INTA. 671 pp.

Cabrera AL. 1968. Flora de la Provincia de Buenos Aires. Tomo IV, Parte 1. Buenos Aires: Colección Científica INTA. 623 pp.

Cabrera A. 1970. Flora de la Provincia de Buenos Aires. Tomo IV, Parte 2. Buenos Aires: Colección Científica INTA. 624 pp.

Correa M. 1969. Flora Patagónica. Tomo VIII, Parte II. Buenos Aires: Colección Científica INTA. 219 pp.

Correa M. 1971. Flora Patagónica. Tomo VIII, Parte VII. Buenos Aires: Colección Científica INTA. 451 pp.

Correa M. 1978. Flora Patagónica. Tomo VIII, Parte III. Buenos Aires: Colección Científica INTA. 581 pp.

Correa M. 1984 a. Flora Patagónica. Tomo VIII, Parte IVa. Buenos Aires: Colección Científica INTA. 559 pp.

Correa M. 1984 b. Flora Patagónica. Tomo VIII, Parte IVb. Buenos Aires: Colección Científica INTA. 309 pp.

Correa M. 1988. Flora Patagónica. Tomo VIII, Parte V. Buenos Aires: Colección Científica INTA. 398 pp.

Correa M. 1998. Flora Patagónica. Tomo VIII, Parte I. Buenos Aires: Colección Científica INTA. 398 pp.

Correa M. 1999. Flora Patagónica. Tomo VIII, Parte VI. Buenos Aires: Colección Científica INTA. 536 pp.

de la Peña MR y Pensiero JF. 2011. Catálogo de nombres comunes de la flora argentina. Santa Fe: Ediciones UNL. 463 pp. 
Dhakar L. 2020. Lightbox. [Acceso 10/04/2020] https://lokeshdhakar.com/projects/lightbox2/.

FileZilla, 2020. [Acceso 15 de abril de 2020] https://filezilla-project.org.

Flora Argentina. c2018. Buenos Aires: Instituto de Botánica Darwinion. [Acceso 15 de abril de 2020] http://www.floraargentina.edu.ar

HO D, 2020. Notepad++. [Acceso 15 de abril de 2020] https://notepad-plus-plus.org/

Kiesling R. 1994. Flora de San Juan. República Argentina. Volumen I. 348 pp.

Kiesling R. 2003. Flora de San Juan. República Argentina. Volumen II. 256 pp.

Kiesling R. 2009. Flora de San Juan. República Argentina. Volumen IV. 735 pp.

Molina AM, Rúgolo de Agrasar ZE (Eds.). 2006. Flora Chaqueña: Colecc. Ci. Inst. Nac. Tecnol. Agropec. 23. 848 pp.

Pensiero JF, HF Gutiérrez, AM Luchetti, E Exner, V Kern, E Brnich, L Oakley, D Prado, JP Lewis. 2005. Flora vascular de la provincia de Santa Fe. Claves para el reconocimiento de las familias y géneros. Catálogo sistemático de las especies. 403 pp. Ediciones UNL.
WampServer, 2020. [Acceso 15 de abril de 2020] http://www.wampserver.es/

XnView, c2013-2020. Reims: XnSoft. [Acceso 15 de abril de 2020] https://www.xnview. com/en/

Zuloaga OF, Belgrano MJ, Zanotti CA. 2019. Actualización del catálogo de las plantas vasculares del Cono Sur. Darwiniana, nueva serie 7(2):208-278.

Zuloaga FO, Rúgolo ZE, Anton AM (Eds.). 2012 a. Flora Vascular de la República Argentina. Monocotyledoneae, Poaceae: Aristidoideae a Pharoideae. Vol. 3, Tomo i. Córdoba: Graficamente Ediciones. (588 p.)

Zuloaga FO, Rúgolo ZE, Anton AM (Eds.). 2012 b. Flora Vascular de la República Argentina. Monocotyledoneae, Poaceae: Pooideae. Vol. 3, Tomo II. Córdoba: Graficamente Ediciones. (523 p.) 